cells have been found in the marrow, this has been ascribed to contamination with peripheral blood. Our patient did not experience any pruritus at all at any stage of the disease and there was no evidence of hyperkeratosis of palms and soles and, in addition to the leonine facies, the patient showed features of Paget's disease which was not noted in previously recorded cases. Also there was anaemia as well as thrombocytopenia which were not found in other cases, although persistent thrombocythaemia was noted in Wilson \& Fielding's case (1953). The presence of these abnormalities possibly indicated bone-marrow involvement and the smears from the sternal marrow aspirate showed numerous Sézary cells, some of them with presence of nucleoli, some showing mitosis. From these findings it was concluded that leukaemic transformation took place in this case and it may be suggested that the site of generation of Sézary cells was the bone marrow as well as the skin. Unlike the cases previously described the disease ran a short course of about 9 months instead of 5 years. This rapid deterioration was attributed to leukaemic transformation.

\section{Acknowledgments}

I am indebted to Dr H. Cohen, Consultant Physician, Salford Royal Hospital, for permission to publish the case and for assistance in making the report; Dr M. C. G. Israëls, Director of Haematology, University of Manchester, for confirmation of the diagnosis and valuable guidance; Dr H. B. Marsden, Consultant Pathologist, Royal Manchester Childrens Hospital, for taking the photomicrograph, and Miss E. L. Street and Miss M. Taylor for their technical assistance.

\section{References}

Alderson, W.E., Barrow, G.I. \& Turner, R.L. (1955) Sézary's syndrome. Brit. med. J. i, 256.

Brody, J.I., Cyprus, E., Kimble, F.E., Mackenzie, D. \& Gables, C. (1962) The Sézary syndrome. A unique cutaneous reticulosis. Arch. intern. Med. 110, 205.

IsRAELS, M.C.G. (1954) Myeloid reticulosis - diagnosis and cause. Lancet, $\mathbf{i}, 978$.

Main, R.A., Goodall, H.B. \& Swanson, W.C. (1959) Sézary's syndrome. Brit. J. Derm. 71, 335.

SeZARY, A. \& Bouvrain, Y. (1938) Erythrodermie avec presence de cellules monstreuses dans derme et sang circulant. Bull. Soc. franc. Derm. Syph. 45, 254.

TASWell, H.F. \& WinfelmanN, R.K. (1961) Sézary syndrome-a malignant reticulocemic erythroderma. J. Amer. med. Ass. 177, 465.

Wilson, H.T.H. \& FieldiNG, J. (1953) Sezary's reticulosis with exfoliative dermatitis. Brit. med. J. i, 1087.

\title{
Localized hirsuties
}

\author{
I. G. SCHRAIBMAN \\ F.R.C.S.(Ed.), F.R.C.S. \\ Late Research Assistant, \\ Department of Surgery, Melbourne University
}

THE DISTRIBUTION of body hair is partly a secondary sex characteristic and thus hormonedependent. Although states of hair deficiency attract more attention than those of hair excess, the latter comprises an interesting group of syndromes, the majority of which are systemic in origin, i.e. associated with hormonal disturbance. There remains, however, a subgroup in which hair overgrowth is a result of purely local factors. It is the purpose of this communication to present two patients in this category and to review the genesis of their condition.

\section{Case No. 1}

Mrs P.W., housewife, aged 39, para 6, gravid 6. She presented in May 1964 with a painful ulcer on the left lower medial side of the leg, present for 2 years. During her last pregnancy, 4 years prior to presentation, the left leg had been continuously swollen. The ulcer appeared 2 years later and varicose veins appeared subsequent to this.

On examination: there were varicose veins in the long saphenous distribution with saphenofemoral incompetence and a healed ulcer $2.5 \mathrm{~cm}$ diameter, $5-7 \cdot 5 \mathrm{~cm}$ above the left medial malleolus. There was minimal surrounding induration and body hair distribution was normal and symmetrical.

On 8 May 1964 she underwent an operation consisting of left sapheno-femoral ligation, stripping of left long saphenous vein and limited subfascial perforator exploration. The wounds healed well. About 2 months after discharge from hospital, she again noticed discomfort at the ulcer site and in relation to the lower part of the perforator exploration wound. The latter area became dusky and indurated, and there was some persistent oedema of the foot. At the same time, new hair 


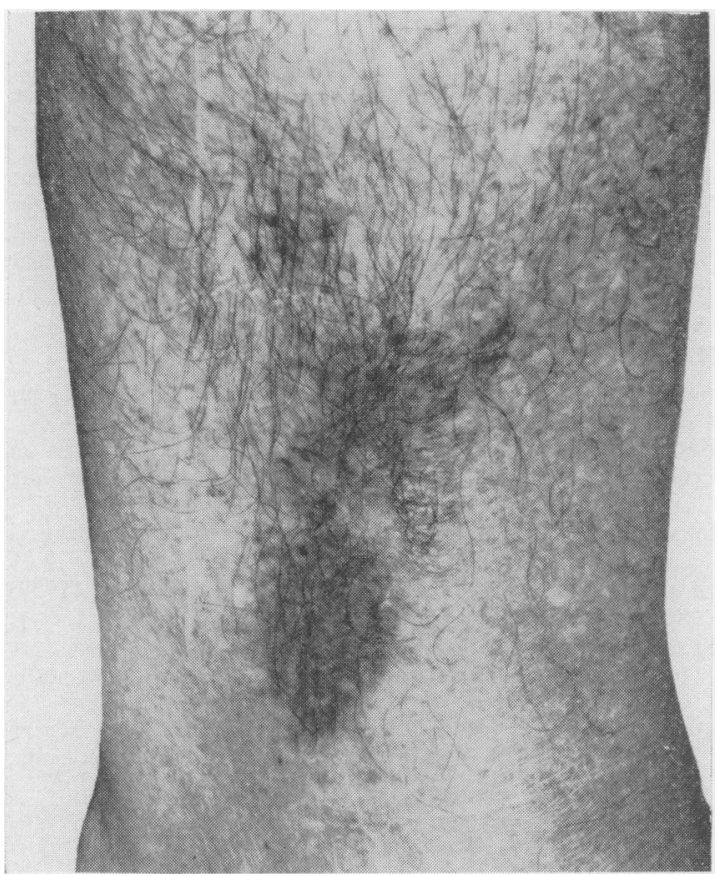

Fig. 1. Mrs P.W. Note localized hirsuties, also increased pigmentation and two scars, the vertical representing the perforator exploration and the horizontal the long saphenous ligation.

appeared in the indurated region and this was sufficient to be a social embarrassment (see Fig. 1).

She had been taking the contraceptive pill ('Anovlar') since her last confinement (4 years ago) and had noticed an increase in weight which had, however, only been noted for the previous 9 months.

The combination of a low-grade, though vascular, inflammatory induration with excessive hair growth, both of which were causing symptoms, suggested the exhibition of superficial X-ray therapy on empirical grounds to produce depilation and de-vascularization. On 31 March 1965 the patient was referred to Dr D. P. Pearce, Radiotherapist to the Alfred Hospital, who kindly agreed to see her and treated her as follows:

A total of 900 rads surface dose was given over 3 weeks (two treatments per week) with an increment of 150 rads per session, to a field $20 \times 20 \mathrm{~cm}$. (Beam generated at $200 \mathrm{kVP}$ with $0.5 \mathrm{~mm}$ copper and $1.0 \mathrm{~mm}$ aluminium filter giving $1.0 \mathrm{~mm}$ of copper half value layer. Focal skin distance $50 \mathrm{~cm}$ ).

When seen 2 months later (2 June 1965) symptoms had completely resolved. On examination there was no local induration, redness, or pedal oedema and the hair distribution was again comparable with the normal side. The final review was on 7 November 1965 (18 months after operation). There was some slight return of hair growth, but no evidence of inflammation and the patient expressed satisfaction with the result.

\section{Case No. 2}

Mrs M.S., process worker, aged 52, para 3, gravid 3. She presented in October 1964 complaining of ulceration of the left lower leg on the lateral aspect for 12 months. Pain was not a feature. During her last pregnancy (21 years prior to presentation) she developed a white leg on the same side.

On examination: there were varicosities of the left long and short saphenous systems. In the lower medial leg there was a localized area of induration, pigmentation and hirsuties. On the lateral aspect there was a pitted ulcer $8 \mathrm{~cm}$ above the lateral malleolus, which was surrounded by a little induration and new hair growth (see Fig. 2).

On 29 October 1964, the patient underwent an operation at the Repatriation General Hospital, Melbourne, comprising sapheno-femoral ligation,

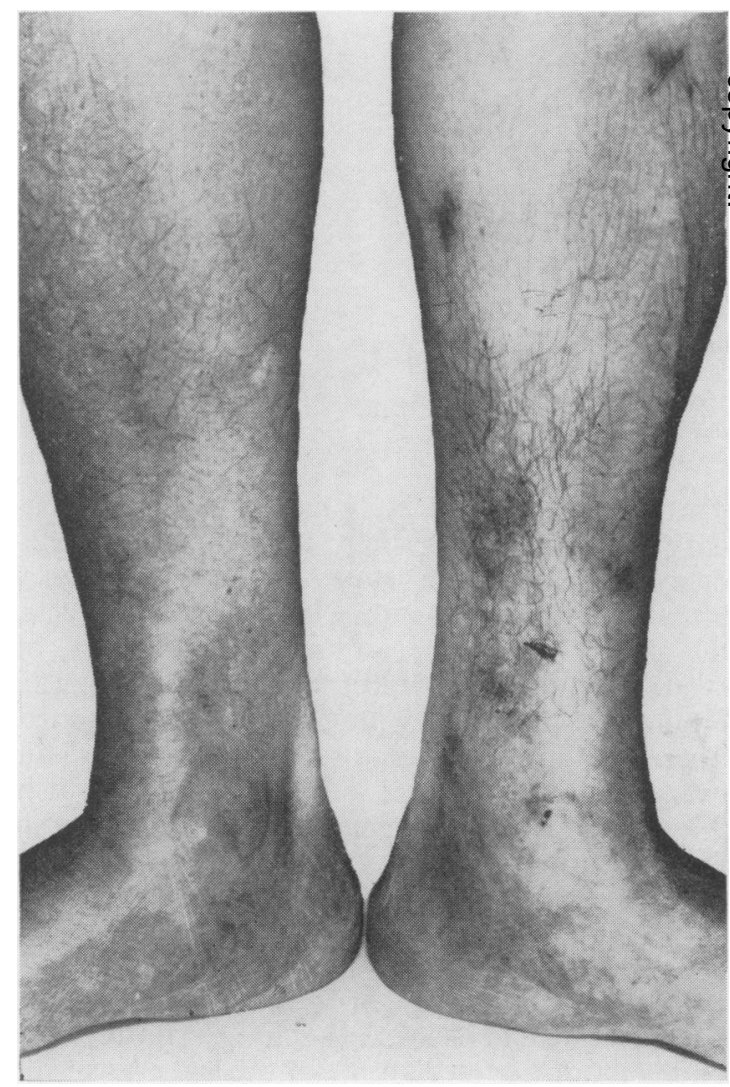

Fig. 2. Mrs M.S. Medial aspect of both lower legs. Note increased pigmentation and hair growth on left. 
ligation of the short saphenous vein and stripping of both veins.

When seen on 24 March 1965 there was less induration on the medial aspect of the leg but the abnormal hair growth persisted, medially and laterally. As this did not cause her any disquiet no further treatment was indicated.

\section{Discussion}

Loss of hair is a sign of vascular insufficiency and it would seem logical to suppose that localized excess of hair is the result of hypervascularity and abundant tissue oxygenation. This view is supported by Ingram \& Brain (1957) who noted new hair growth on parts treated with frequent hot fomentations, and by Behrman (1960) who states that this phenomenon may be observed at sites of prolonged physical irritation under plaster of paris casts. This might also be explained as being due to absence of rubbing of clothing against the hairy skin.

Allen, Barker \& Hines (1955) observed that the new hair growth may be associated with congenital arteriovenous fistula, while Sutton \& Sutton (1949) mention hair growth in denervated areas, which they ascribe to lack of friction.

Excess new hair has been described in the skin overlying chronic osteomyelitis of the tibia (Schüller \& Frost, 1956). On the other hand, but still in support of the theory that excess hair growth only occurs where tissues are well oxygenated, Dodd \& Cockett (1956) believe that there is a tendency for varicose veins to be associated with lack or loss of hair, assuming that varicose disease creates conditions of hypoxia. Perhaps the most interesting contribution is by Ghadially (1958) who found that during the quiescent phase of the hair growth cycle in the rabbit, a tuft of new hair would arise at the site of a small incision in a shaven area.

The opposing view is that follicular activity precedes, i.e. evokes, increased vascularity (Ebling \& Johnson, 1959). This concept raises more questions than it answers.

In both patients presented here, localized hirsuties was associated with a low-grade inflammatory reaction and with (presumably) increased vascularity. In Mrs P.W. the condition developed after surgery and the possibility arises that this was a granulomatous response to suture material. The only buried sutured material was 00 plain catgut, which is quickly absorbed and is unlikely to cause a granuloma persisting for 8 months.

The other possibility is that the lesion represented a persistent superficial thrombophlebitis in association with the taking of oral contraceptives and perhaps precipitated by local surgery. This cannot be discounted, but the common factor in both patients is that they presented with the complications of deep vein thrombosis.

\section{Summary}

Two patients are presented who both showed localized non-hormonal new hair growth associated with the complications of deep vein thrombosis in limbs with varicose veins. The scanty literature on localized hirsuties is reviewed and support given to the belief that this phenomenon arises as a result of localized hypervascularity.

\section{Acknowledgments}

I would like to thank Professor M. R. Ewing for permission to manage the first patient and Dr D. P. Pearce for seeing and treating her. I am grateful to Mr I. Heinz, Surgeon Consultant to the Repatriation Department, for permission to examine the second patient.

\section{References}

Allen, E.V., Barker, N.W. \& Hines, F.A. (1955) Peripheral Vascular Disease, p. 418. Saunders, Philadelphia.

Behrman, H.T. (1960) Diagnosis and management of hirsutism. J. Amer. med. Ass. 172, 1924.

DodD, H. \& CocketT, F.B. (1956) The Pathology and Surgery of the Veins of the Lower Limb, p. 80. Livingstone, London.

Ebling, F.J. \& Johnson, E. (1959) Hair growth and its relation to vascular supply in rotated skin grafts and transposed flaps in the albino rat. J. Embryol. exp. Morph. $7,417$.

GHADIALLY, F.N. (1958) Effect of trauma on growth of hair. Nature (Lond.), 181, 993.

InGRAM, J.T. \& BRAIN, R.T. (1957) Sequeira's Disease of the Skin, p. 776. Churchill, London.

Schuller, P.A. \& Frost, J.A. (1956) Osteomilitis cronica de perone e hipertrichosis localizada. Medicina (Madrid), 24,360 .

Sutton, P. \& Sutton, R. (1949) Handbook of Diseases of Skin, p. 664. Mosby, St Louis. 